\title{
THERMAL ANALYSIS OF DIFFERENT CONFIGURATIONS FOR BUILDING INSULATION SYSTEMS WITH ACTUAL MATERIALS USING REAL SOLAR RADIATION AND TEMPERATURE DATA
}

\author{
C. B. P. G. Sa, \\ M. F. Curi \\ Centro Federal de Educação Tecnológica Celso \\ Suckow da Fonseca \\ Department of Mechanical Engineering, \\ Rio de Janeiro, Itaguaí, Brazil \\ brenuu844@gmail.com \\ marcos.curi@cefet-ri.br \\ Received: Dec 07, 2020 \\ Revised: Jan 19, 2021 \\ Accepted: Feb 26, 2021

\section{NOMENCLATURE}

$\begin{array}{ll}\text { A } & \text { area, } \mathrm{m}^{2} \\ \mathrm{c}_{\mathrm{p}} & \text { specific heat, } \mathrm{J} /(\mathrm{kg} . \mathrm{K}) \\ \mathrm{h} & \text { convective coefficient, } \mathrm{W} /\left(\mathrm{m}^{2} . \mathrm{K}\right) \\ \mathrm{I} & \text { solar radiation, } \mathrm{W} / \mathrm{m}^{2} \\ \mathrm{k} & \text { thermal conductivity, } \mathrm{W} /(\mathrm{m} . \mathrm{K}) \\ \mathrm{t} & \text { time, } \mathrm{s} \\ \mathrm{T} & \text { temperature, } \mathrm{K} \\ \mathrm{x}, \mathrm{y}, \mathrm{z} & \text { spatial variables, } \mathrm{m}\end{array}$

\begin{abstract}
Thermal insulation is present in several engineering areas, such as in civil construction, in industrial ovens, in satellites and launch vehicles and even in domestic applications, such as refrigerators. This work aims to present multilayer insulation for civil construction, thus reducing electrical energy expenditure on air conditioning the environment and increasing thermal comfort. To determine the heat flow through the wall, it was necessary to solve the heat diffusion equation in rectangular Cartesian coordinates for each insulation layer, and the boundary conditions of each differential equation depend on the neighboring layers, thus forming a system of equations. The Wolfram Mathematica computational software was used to solve the mathematical equations. The heat flow was determined for the four seasons of the year throughout the day for different configurations of thermal insulation, varying the insulating material and its thickness. After analyzing the results, it was possible to observe the great efficiency of the models with thermal insulation compared to traditional walls, making the internal wall's temperature profile more constant throughout the day.
\end{abstract}

Keywords: thermal walls; heat transfer; thermal comfort; insulation systems

\section{Greek symbols}

$\begin{array}{ll}\alpha & \text { thermal absorptivity } \\ \varepsilon & \text { thermal emissivity } \\ \rho & \text { density, } \mathrm{kg} / \mathrm{m}^{3} \\ \Phi & \text { heat flux, } \mathrm{W} / \mathrm{m}^{2}\end{array}$

\section{INTRODUCTION}

Thermal insulation is widely used in several areas, progressively adapted for better performance in each use. It can be used to increase the thermal comfort, as in buildings, avoiding heat gain or loss, thus making it easier to maintain the desired temperature, or as an essential tool for the operation of a system, as in cryogenic tanks and space applications.

The thermal insulation of an environment proposed by Guo et al., (2012) can save about $5.8 \mathrm{kWh} /(\mathrm{m} 2$. Month) of electrical energy with air conditioning, considering that a medium can maintain its temperature, no energy will be required to regulate it. Baetens et al., (2010) and Theodosiou and Papadopoulos (2008) also studied the effects of thermal insulation on civil construction, thus combining energy savings with the comfort of the airconditioned environment.

There are several ways to insulate a medium thermally. Using several layers that act as conductive barriers Ozel and Pihtili (2007). Baetens et al., (2010) show the Vacuum Insulation Panels (VIPs). This insulation consists of the application of vacuum in an encapsulated microporous material, confirming that the Kyoto protocol requirements would be easily achieved with $2 \mathrm{~mm}$ of this insulation in all buildings not thermally insulated. Reflective insulation consists of radiant barriers capable of reducing infrared radiation transfer between distant objects, Fairey (1986). Moreover, the multilayer insulation consists of the combined effect of reflective barriers capable of reflecting almost $100 \%$ of the radiation, Finckenor and Dooling (1999). Thus, with several applications, such as isolation of cryogenic tanks, Jacob et al. (1992), and thermal protection to keep reusable launch vehicles within acceptable limits during re-entry into the atmosphere, Daryabeigi (2002).

This work aims to analyze thermal insulation for civil construction with actual materials like PET, Polystyrene, among others, to reduce the thermal exchange by conduction and radiation. Three models 
were simulated: a traditional wall and the other two walls with different thermal insulation forms. The heat flux through these walls throughout the day was calculated during different periods of the year. Thus, it is possible to verify the thermal efficiency promoted by the models and materials studied when compared to traditional walls. The computer software Wolfram Mathematica was used to perform the simulations.

\section{PROBLEM FORMULATION AND MATHEMATICAL MODEL}

The model consists of " $n$ " layers of thermal insulation, as can be seen in Fig. 1a. The mode of heat transfer for each layer is described throughout this chapter.

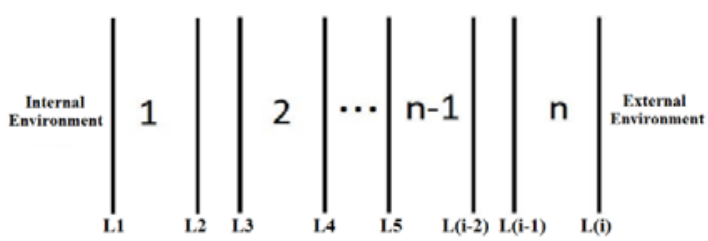

Figure 1a. Model with "n” layers of insulation.

To determine the temperature profile in the solids, the heat diffusion equation was used. This differential equation in cartesian coordinates is given below by Eq. (1),

$$
\begin{gathered}
\frac{\partial}{\partial t}\left(k \frac{\partial T}{\partial x}\right)+\frac{\partial}{\partial t}\left(k \frac{\partial T}{\partial y}\right)+\frac{\partial}{\partial t}\left(k \frac{\partial T}{\partial z}\right)+q \\
=\rho c_{p} \frac{\partial T}{\partial t}
\end{gathered}
$$

Newton's law of cooling, Eq. (2), describes the heat flux $(\Phi)$ through convection, when a surface is in contact with a liquid or a gas, which occurs at both ends of the insulation.

$$
\Phi=h\left(T_{s}-T_{\infty}\right)
$$

Eq. (3) describes the heat gain from solar radiation that occurs on the external wall, knowing that $\alpha$ is the absorptivity of the material and $I$ solar radiation.

$$
\Phi=\alpha . I
$$

The exchange of heat by radiation takes place between the layers of insulation and does not need a physical medium and can be exchanged in a vacuum. Eq. (4) describes the heat exchanged by radiation between surfaces in cartesian coordinates.

$$
\Phi=\frac{\sigma\left(T_{1}^{4}-T_{2}^{4}\right)}{\frac{1-\varepsilon_{1}}{\varepsilon_{1} A_{1}}+\frac{1}{A_{1} F_{12}}+\frac{1-\varepsilon_{2}}{\varepsilon_{2} A_{2}}}
$$

The forming factor $\left(F_{12}\right)$ represents the fraction of radiation leaving the surface $A_{1}$ and is intercepted by $A_{2}$, it can be calculated by Eq. (5).

$$
F_{12}=\frac{1}{A_{1}} \int_{A_{1}} \int_{A_{2}} \frac{\cos \left(\theta_{1}\right) \cdot \cos \left(\theta_{2}\right)}{\pi \cdot R^{2}} d A_{1} d A_{2}
$$

Knowing that $A_{1}$ and $A_{2}$ are the surfaces that are exchanging heat for radiation and that $\theta_{1}$ and $\theta_{2}$ are the angles formed between the straight line connecting the area elements $d A_{1}$ and $d A_{2}$ with normal to $d A_{1}$ and $d A_{2}$ respectively, as seen in Fig.1b. Solving Eq. (5) and replacing Eq. (4), we obtain Eq. (6).

$$
\Phi=\frac{\sigma\left(T_{1}^{4}-T_{2}^{4}\right)}{\frac{1}{\varepsilon_{1}}+\frac{1}{\varepsilon_{2}}-1}
$$

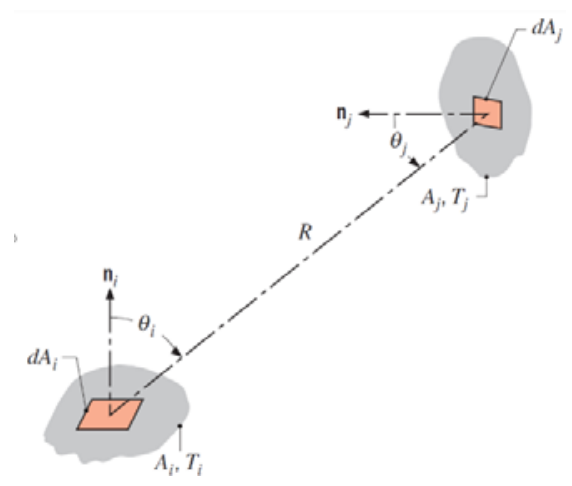

Figure 1b. Exchange of radiation between surfaces $A_{\mathrm{i}}$ and $A_{\mathrm{j}}$. Incropera et. al., (2011)

Eq. (7) was used to calculate the heat flow.

$$
\Phi=-\left.k \frac{\partial T}{\partial x}\right|_{x=L 2}
$$

Three different wall models were studied, as shown in Fig. 1. The heat flow through the walls was calculated over a day in 4 different months, March, June, September and December. The external temperature used varied in each simulation where the internal temperature was fixed in $20^{\circ} \mathrm{C}$. The external and internal convective coefficients were $28 \mathrm{~W} / \mathrm{m}^{2} . \mathrm{k}$ e $6 \mathrm{~W} / \mathrm{m}^{2} . \mathrm{k}$, respectively, according to Dias (2018).

Fig. 2a shows configuration 1, a traditional wall composed of $0.15 \mathrm{~m}$ of brick. Fig. 2b shows configuration 2, a wall with thermal insulation, composed of $0.15 \mathrm{~m}$ of brick on the left side, outer layer, and $0.15 \mathrm{~m}$ of insulating material on the right side, inner layer. Fig. 2c shows configuration 3, a wall with the inner and outer layers equal to Fig. $3 b$, but with a $1 \mathrm{~mm}$ vacuum layer between them and aluminum sheets on the right surface of the outer layer and on the left surface of the inner layer, acting as a reflective insulation. 


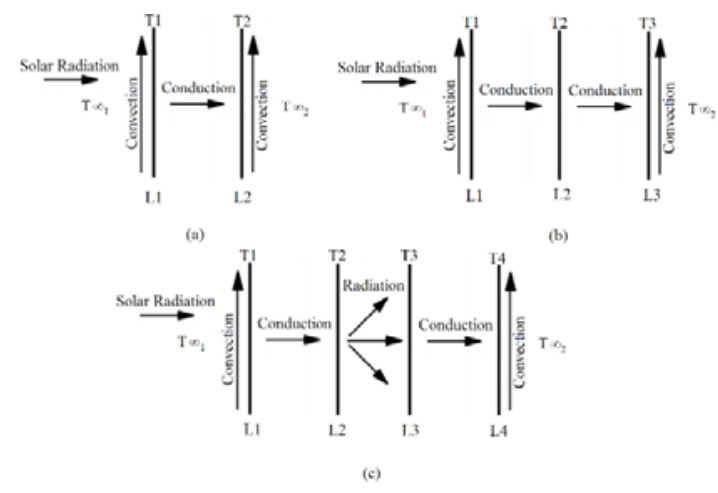

Figure 2. a) Traditional wall. b) Wall with thermal insulation. c) Wall with vacuum and thermal insulation.

\section{Boundary Condition of Configuration 1}

This configuration contains only one layer, so it exchanges heat with the external medium through radiation and convection, Eq. (8), and loses heat to the internal medium through convection, Eq. (9), being k the thermal conductivity of the brick.

$$
\begin{gathered}
\alpha . I+h_{1}\left(T_{\infty 1}-T_{1}\right)=-\left.k \frac{\partial T}{\partial x}\right|_{x=L 1} \\
-\left.k \frac{\partial T}{\partial x}\right|_{x=L 2}=h_{2}\left(T_{2}-T_{\infty 2}\right)
\end{gathered}
$$

\section{Boundary Condition of Configuration 2}

This configuration contains two layers, the outer layer Exchanges heat with the external environment by radiation and convection and, Eq. (10) and loses heat to the inner layer by conduction, Eq. (11). Where $k_{1}$ is the thermal conductivity of the brick and $k_{2}$ is the PET foam thermal conductivity.

$$
\begin{gathered}
\alpha . I+h_{1}\left(T_{\infty 1}-T_{1}\right)=-\left.k \frac{\partial T_{a}}{\partial x}\right|_{x=L 1} \\
-\left.k_{1} \frac{\partial T_{a}}{\partial x}\right|_{x=L 1}=-\left.k_{2} \frac{\partial T_{b}}{\partial x}\right|_{x=L 2}
\end{gathered}
$$

The inner layer exchanges heat with the outer layer by conduction, Eq. (11) and exchanges heat with the inner medium by convection, Eq (12).

$$
-\left.k_{2} \frac{\partial T_{b}}{\partial x}\right|_{x=L 3}=h_{2}\left(T_{2}-T_{\infty 2}\right)
$$

\section{Boundary Condition of Configuration 3}

Configuration 3 also has two layers, but they are separated by vacuum, so the outer layer exchanges heat with the external medium by radiation and $\mathrm{T}$ convection, Eq. (10), and loses heat to the inner layer by radiation, Eq. (13).

$$
-\left.k_{1} \frac{\partial T_{a}}{\partial x}\right|_{x=L 2}=\frac{\sigma\left(T_{2}^{4}-T_{3}^{4}\right)}{\frac{1}{\varepsilon_{1}}+\frac{1}{\varepsilon_{2}}-1}
$$

Being $\varepsilon_{1}$ and $\varepsilon_{2}$ the emissivities of the outer and inner layers respectively and $\sigma$ the constant of StefanBoltzmann. The inner layer exchanges heat with the outer layer for radiation, Eq. (14), and exchanges heat with the inner medium by convection, Eq (15).

$$
\begin{gathered}
\frac{\sigma\left(T_{2}^{4}-T_{3}^{4}\right)}{\frac{1}{\varepsilon_{1}}+\frac{1}{\varepsilon_{2}}-1}=-\left.k_{2} \frac{\partial T_{b}}{\partial x}\right|_{x=L 3} \\
-\left.k \frac{\partial T_{b}}{\partial x}\right|_{x=L 4}=h_{2}\left(T_{4}-T_{\infty 2}\right)
\end{gathered}
$$

\section{RESULTS AND DISCUSSION}

The mathematical model was simulated in Wolfram Mathematica. For this first analysis, the temperature of the external environment used was the average temperature of each month, found at the Instituto Nacional de Meteorologia (INMET). It was considered a wall oriented to the west, at latitude $23^{\circ} 30^{\prime}$, taking the solar radiation every hour between 6 am and $6 \mathrm{pm}$, Frota and Schiffer (1987). To analyze the heat flux through each wall, the maximum heat flux of every month for all configuration were compared, as is shown in Tab. 1.

Table 1. Values in $\mathrm{W} / \mathrm{m}^{2}$ of the maximum heat flux for each setting in four different months.

\begin{tabular}{|c|c|c|c|}
\hline & Config. 1 & Config. 2 & Config. 3 \\
\hline March & 24.648 & 1.368 & 0.917 \\
\hline June & 12.610 & 0.696 & 0.461 \\
\hline September & 15.859 & 0.878 & 0.581 \\
\hline December & 23.861 & 1.325 & 0.883 \\
\hline
\end{tabular}

As expected, due to the presence of a thermal insulating material in configurations 2 , it is possible to note the difference in the heat flux between configurations 1 and 2 . Configuration 3 , when compared to configuration 2 is a good alternative to intensify the thermal insulation, since the heat flux of configuration 2 was greater $49.18 \%$ in March, $50.97 \%$ in June, $51.11 \%$ in September and $50.05 \%$ in December than the configuration 3 heat flux.

Figure 3 shows the heat flux through each wall throughout the day for different seasons. To improve the comparison between months, the scale for every month on the charts was maintained. Each month has similar profiles, but it is possible to observe that March and December have slightly greater amplitudes than June and September and are also shifted upwards. The difference in heat flux between 12 am and $4 \mathrm{pm}$ is $8.635 \mathrm{~W} / \mathrm{m}^{2}$ for configuration $3,0.480 \mathrm{~W} / \mathrm{m}^{2}$ for configuration 2 and $0.331 \mathrm{~W} / \mathrm{m}^{2}$ for configuration 1 , thus showing great efficiency in the thermal insulation of configurations 2 and 3 . 


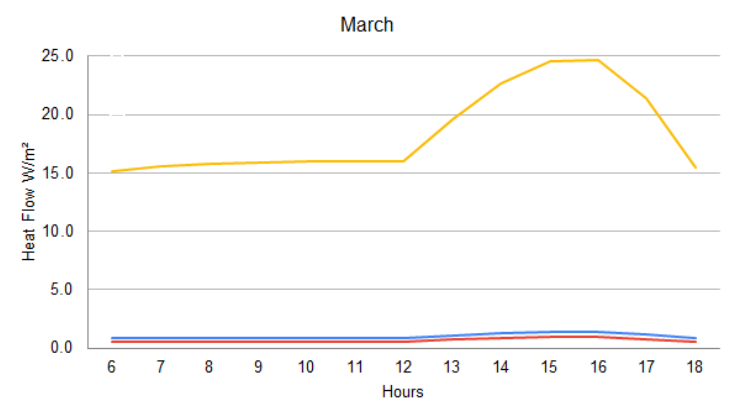

- Configuration $3-$ Configuration $1-$ Configuration 2

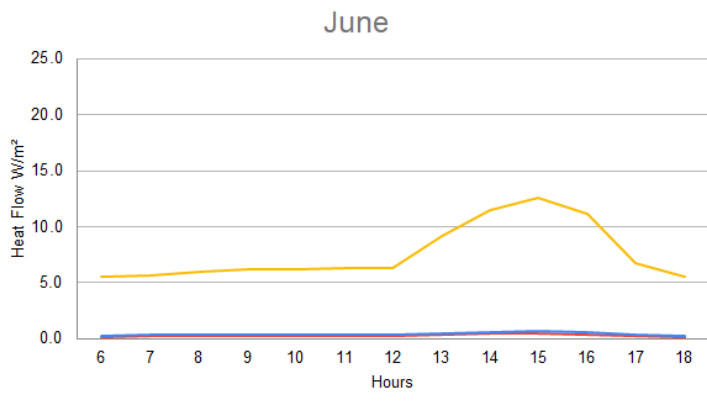

- Configuration 3 - Configuration 1 - Configuration 2

September

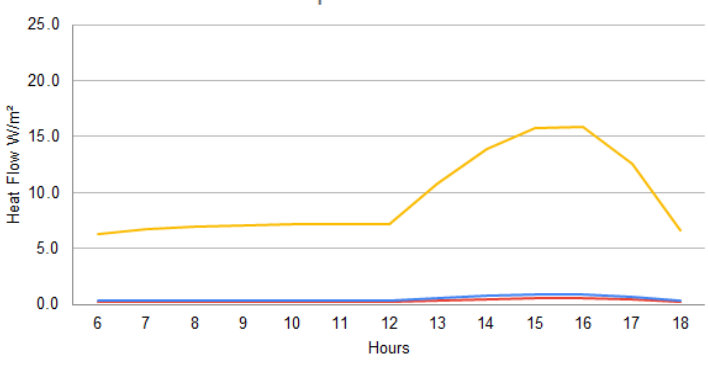

- Configuration 3 - Configuration $1-$ Configuration 2

December

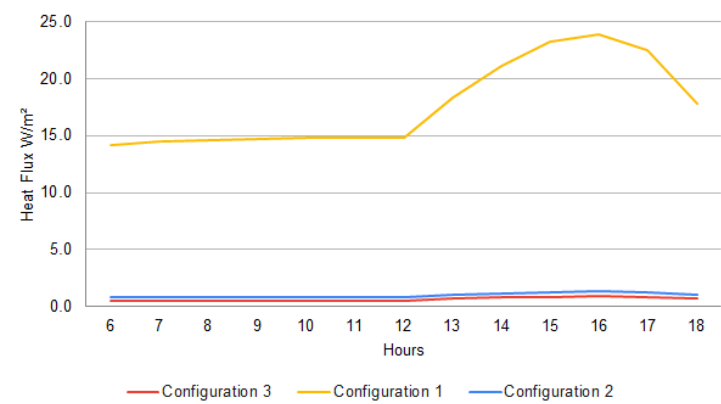

Figure 3. Heat flux throughout the day in the three configurations each month.
It was also simulated a model of three layers separated by $1 \mathrm{~mm}$ of vacuum, the inner and outer layers are made of brick, and the intermediate layer is fiberglass. All of them with $0.1266 \mathrm{~m}$, thus forming a wall of $0.4 \mathrm{~m}$, and only the layer intermediate has aluminum sheets, reflective shields at both ends. The data of the temperature of the external environment, varying throughout the day, and solar irradiation, present in Fig. 4, were taken from Fidaros et al., (2010). This insulation was compared with a common wall, configuration 1 , which is composed only with a $0.15 \mathrm{~m}$ of brick and the results are shown in Fig. 4 and Fig. 5.
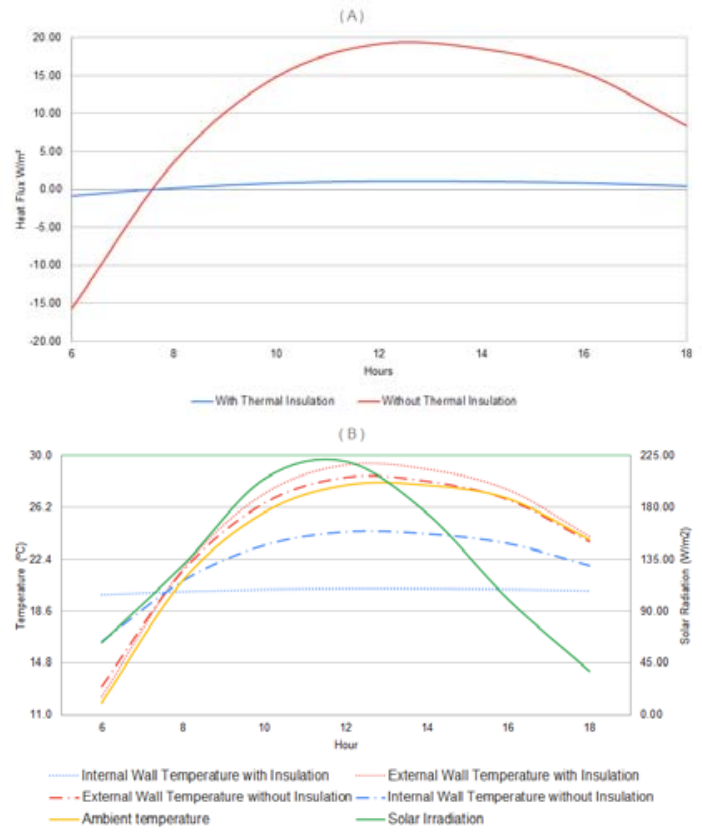

Figure 4. Heat flux through each wall $x$ Hour on the left and Temperature (right vertical axis), Solar Irradiation (Left vertical axis) x Time.

It is possible to observe that the amplitude of the heat flux throughout the day is smaller in the wall with thermal insulation, preventing heat loss in the internal environment when its temperature is higher than the external environment. The internal wall temperature remained constant during the day in the thermally insulated environment, closer to the internal temperature of $20^{\circ} \mathrm{C}$. The temperature profile is shown every two hours in Fig. 5 for the common and thermally insulated wall to analyze the heat exchange in each material. 
From Fig. 5, it is possible to observe a lower variation in the temperature of the inner wall when thermal insulation. Showing that the inner wall does not well perceive variations in temperature and solar radiation on the outer wall. Even the layers having the same length in the insulating layer, the temperature profile's inclination is greater than in the bricklayer, showing that the temperature variation in the insulating material is also greater. The temperature variation between the layers shows that the vacuum between them is an excellent thermal insulator, which demands short thickness to achieve lower temperatures.
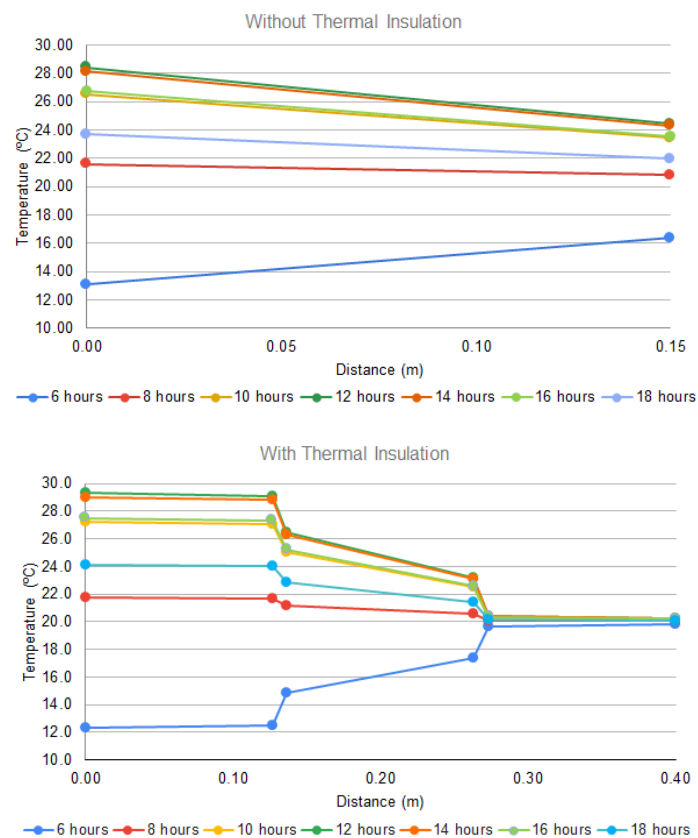

Figure 5. Temperature profile on both walls.

Figure 6 depicted the influence of the insulating material and its thickness, with the same configuration as in Fig. 3. The temperature of the external environment was fixed at $40^{\circ} \mathrm{C}$, the solar radiation used was the annual average for the city of Rio de Janeiro, available in INMET, the graphs (A) and (B), have a vacuum between the layers and the graphs (C) and (D) does not.

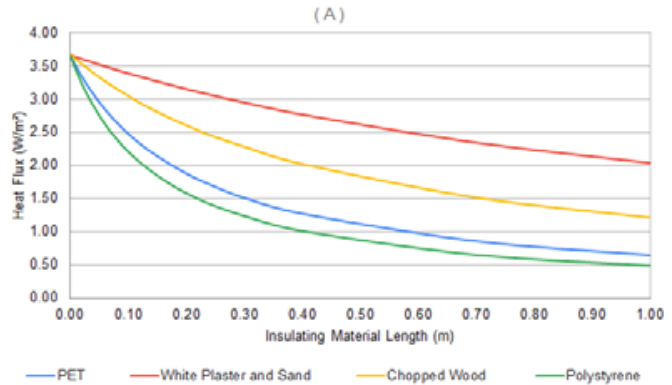

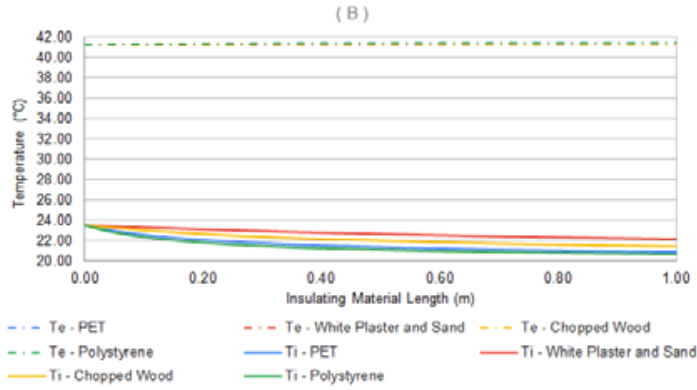

(C)
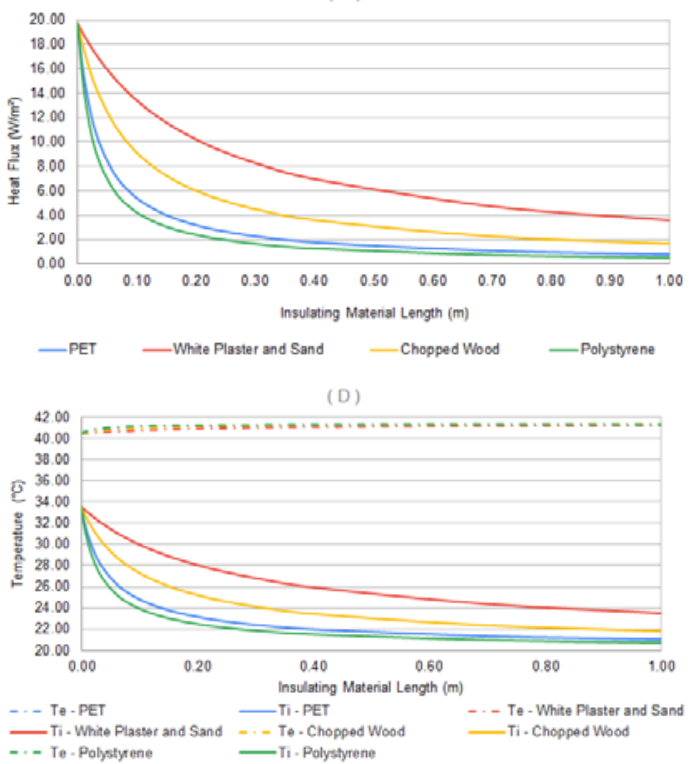

Figure 6. Variation in the thickness of the insulating material. Graphs (A) and (B) with vacuum between

layers and graphs (C) and (D) without vacuum between layers.

The vacuum model achieves good results for thermal insulation, even with a thinner wall. To achieve approximately $2.33 \mathrm{~W} / \mathrm{m}^{2}$, the vacuum model - Fig. 6 (A) - needs $0.12 \mathrm{~m}$ of the PET insulation material thickness and $0.29 \mathrm{~m}$ for the model represented by Fig. $6(\mathrm{C})$. To reach the internal wall temperature (Ti) of $22^{\circ} \mathrm{C}$, it is necessary $0.15 \mathrm{~m}$ of insulation material for the vacuum model - Fig. 6 (A) - and $0.28 \mathrm{~m}$ for the model without vacuum model, Fig. 6 (C), using polystyrene as an insulator.

In Tab. 2 and Tab.3, it is possible to observe that even in the absence of insulating material, the difference in the two models' heat flux is large. This is due to the vacuum and the aluminum sheets present in the model of Tab.3. However, increasing the insulating layer, this difference becomes progressively smaller. It is possible to observe that for $1 \mathrm{~m}$, the heat flux values between the two models are very close. 
Table 2. Heat flux $\left[\mathrm{W} / \mathrm{m}^{2}\right]$ without vacuum between the layer for different materials and thickness.

\begin{tabular}{|c|c|c|c|c|c|}
\hline $\begin{array}{c}\text { Thickness } \\
{[\mathbf{m}]}\end{array}$ & $\mathbf{0 . 0 0}$ & $\mathbf{0 . 0 6}$ & $\mathbf{0 . 1 2}$ & $\mathbf{0 . 4 0}$ & $\mathbf{1 . 0 0}$ \\
\hline PET & 19.64 & 7.49 & 4.70 & 1.73 & 0.74 \\
\hline $\begin{array}{c}\text { White } \\
\text { Plaster and } \\
\text { Sand }\end{array}$ & 19.64 & 15.32 & 12.60 & 6.98 & 3.62 \\
\hline $\begin{array}{c}\text { Chopped } \\
\text { Wood }\end{array}$ & 19.64 & 11.53 & 8.24 & 3.59 & 1.64 \\
\hline Polystyrene & 19.64 & 6.13 & 3.69 & 1.31 & 0.55 \\
\hline
\end{tabular}

Table 3. Heat Flux $\left[\mathrm{W} / \mathrm{m}^{2}\right]$ with vacuum between the layer for different materials and thickness.

\begin{tabular}{|l|c|c|c|c|c|}
\hline Thickness [m] & $\mathbf{0 . 0 0}$ & $\mathbf{0 . 0 6}$ & $\mathbf{0 . 1 2}$ & $\mathbf{0 . 4 0}$ & $\mathbf{1 . 0 0}$ \\
\hline PET & 3.65 & 2.84 & 2.33 & 1.27 & 0.64 \\
\hline $\begin{array}{l}\text { White Plaster } \\
\text { and Sand }\end{array}$ & 3.65 & 3.50 & 3.34 & 2.77 & 2.04 \\
\hline Chopped Wood & 3.65 & 3.26 & 2.94 & 2.02 & 1.21 \\
\hline Polystyrene & 3.65 & 2.63 & 2.05 & 1.02 & 0.49 \\
\hline
\end{tabular}

\section{CONCLUSIONS}

The thermal insulation studied was shown to be very efficient when compared to traditional walls, showing a little variable heat flow profile even at different epochs of the year where the difference in heat flow between 12 am and $4 \mathrm{pm}$ reached $8.635 \mathrm{~W} / \mathrm{m}^{2}$ for configuration $3,0.480 \mathrm{~W} / \mathrm{m}^{2}$ for configuration 2 and $0.331 \mathrm{~W} / \mathrm{m}^{2}$ for configuration 1 . It was also possible to analyze thermal insulation variations, such as thickness, material, and vacuum presence.

The vacuum insulation models proved to be a good option when space is a limitation of the system. Without vacuum, the model was necessary more than 6 times the amount of PET to reach the same heat flux as the model with vacuum and 1.86 times the amount of polystyrene to reach the same internal wall temperature.

The material used as an insulator also greatly influences the insulation's efficiency. The insulation thickness of white plaster and sand was 8 times greater than the polystyrene material to maintain a heat flux of $3.06 \mathrm{~W} / \mathrm{m}^{2}$ and $9.25 \mathrm{~W} / \mathrm{m}^{2}$ with and without a vacuum, respectively.

\section{REFERENCES}

Baetens, R. Jelle, B.P. Thue, J.V. Tenpierik, M.J. Grynning, S. Uvsløkk, S. and Gustavsen, A., 2010. "Vacuum insulation panels for building applications: A review and beyond". Energy and Buildings, Vol. 42, pp. $147-172$.

Daryabeigi, k., 2002. "Thermal Analysis and Design Optimization of Multilayer Insulation for Reentry Aerodynamic Heating”. Journal of Spacecraft and Rockets, Vol. 39, No. 4, pp. 509-514.
Dias, P.F.L. Sousa Filho, L.M. and Fonseca, W.D.P., 2018. "Numerical Investigation Of Heat Transfer in a Multi-Layer Wall Used in Brazilian Buildings" Proceedings of the 5th International Conference of Fluid Flow, Heat and Mass Transfer FFHMT 2018. Niagara Falls, Canada.

Fairey, P., 1986. "Radiant Energy Transfer and Radiant Barrier Systems in Buildings". Florida Solar Energy Center, No. FSEC-DN-6-86.

Fidaros, D.K. Baxevanou, C.A. Bartzanas, T. and Kittas, C., 2010. "Numerical simulation of thermal behavior of a ventilated arc greenhouse during a solar day". Renewable Energy, Vol. 35, pp.1380-1386.

Finckenor, M.M. Dooling, D., 1999. "Multilayer Insulation Material Guidelines". National Aeronautics Space Administration, No. NASA/TP--1999-209263.

Frota, A.B. and Schiffer, S.R., 1987. Manual de Conforto Térmico, 5 nd edition.

Guo, W. Qiao, X. Huang, Y. Fanga, M. and Han, X., 2012. "Study on energy saving effect of heatreflective insulation coating on envelopes in the hot summer and cold winter zone". Energy and Buildings, Vol. 50, pp. 196-203.

Incropera, F.P. Dewitt, D.P. Bergman, T.L and Lavine, A.S., 2007. Fundamentals of Heat and Mass Transfer, 7nd edition.

INMET. "Normais Climatológicas do Brasil" Instituto Nacional de Meteorologia. 14 Mar. 2020 $<$ http://www.inmet.gov.br/portal/index.php?r=clima/ normaisClimatologicas $>$

Jacob, S. Kasthurirengan, S. and Karunanithi, R., 1992 "Investigations into the thermal performance of multilayer insulation (300- $77 \mathrm{~K}$ ) Part 1: Calorimetric studies”. Cryogenics, Vol. 32, No. 12, pp. 1137-1146.

Ozel, M. and Pihtili, K., 2007. "Optimum location and distribution of insulation layers on building walls with various orientations". Building and Environment, Vol. 42, pp. 3051-3059.

Theodosiou, T.G. and Papadopoulos, A.M., 2008. "The impact of thermal bridges on the energy demand of buildings with double brick wall constructions". Energy and Buildings, Vol. 40, pp. 2083-2089. 